\title{
Does Exposure to the Refugee Crisis Make Natives More Hostile?
}

\section{DOMINIK HANGARTNER ETH Zurich and London School of Economics}

ELIAS DINAS European University Institute and University of Oxford

MORITZ MARBACH ETH Zurich

KONSTANTINOS MATAKOS King's College London

\section{DIMITRIOS XEFTERIS University of Cyprus}

\begin{abstract}
1 lthough Europe has experienced unprecedented numbers of refugee arrivals in recent years, there exists almost no causal evidence regarding the impact of the refugee crisis on natives' attitudes, policy preferences, and political engagement. We exploit a natural experiment in the Aegean Sea, where Greek islands close to the Turkish coast experienced a sudden and massive increase in refugee arrivals, while similar islands slightly farther away did not. Leveraging a targeted survey of 2,070 island residents and distance to Turkey as an instrument, we find that direct exposure to refugee arrivals induces sizable and lasting increases in natives' hostility toward refugees, immigrants, and Muslim minorities; support for restrictive asylum and immigration policies; and political engagement to effect such exclusionary policies. Since refugees only passed through these islands, our findings challenge both standard economic and cultural explanations of anti-immigrant sentiment and show that mere exposure suffices in generating lasting increases in hostility.
\end{abstract}

\section{INTRODUCTION}

$\mathbf{R}$ ecent years have seen the highest levels of forced displacement, up to 66 million, since the aftermath of World War II. Since 2015, more than three million individuals, predominantly from Muslimmajority countries such as Syria, Afghanistan, and Iraq,

Dominik Hangartner, Associate Professor, Center for Comparative and International Studies, ETH Zurich; Immigration Policy Lab, Stanford University and ETH Zurich; and Department of Government, London School of Economics, d.hangartner@lse.ac.uk.

Elias Dinas, Swiss Chair in Federalism, Democracy and International Governance, Robert Schuman Centre for Advanced Studies and Department of Social and Political Sciences, European University Institute; and Associate Professor, Department of Politics and International Relations, University of Oxford, elias.dinas@eui.eu.

Moritz Marbach (iD), PostDoc, Center for Comparative and International Studies, ETH Zurich; and Immigration Policy Lab, Stanford University and ETH Zurich, moritz.marbach@gess.ethz.ch.

Konstantinos Matakos, Assistant Professor, Department of Political Economy, King's College London, konstantinos.matakos@kcl.ac.uk.

Dimitrios Xefteris, Assistant Professor, Department of Economics, University of Cyprus, xefteris.dimitrios@ucy.ac.cy.

The survey was fielded by the Survey Unit of the University of Macedonia according to our sampling frame and in line with the ethics policy of the London School of Economics and Political Science for human subjects research. DH, ED, MM, KM, and DX conceived and designed the research; $\mathrm{ED}, \mathrm{DH}$, and $\mathrm{KM}$ designed the survey; $\mathrm{ED}, \mathrm{KM}$, MM, DX, and DH helped with data collection; $\mathrm{MM}$ and DH performed statistical analyses; and DH, MM, KM, and ED wrote the manuscript. We thank Alexandra Dufresne, Marc Helbling, Dan Hopkins, and David Laitin for detailed comments. This paper benefited from the questions and suggestions from numerous seminar and conference participants. The usual disclaimer applies. ED and KM acknowledge financial support from the British Academy for a Small Leverhulme Grant (project number CTR00340) and DH support from the Leverhulme Trust. Replication files are available at the American Political Science Review Dataverse: https://doi.org/10.7910/DVN/XGVQDT.

Received: August 15, 2017; revised: April 5, 2018; accepted: November 6, 2018. First published online: December 27, 2018. have applied for asylum in Europe alone. Although applications declined in 2016 and 2017 after the implementation of the EU-Turkey Agreement, overall numbers are expected to remain high as asylum seekers continue to flee protracted conflicts and persecution.

The dramatic increase in asylum seekers and the chaotic management of refugee flows have dominated news cycles across Europe, led to social tensions and political conflict, and triggered, at times, even violent political backlash (Bansak, Hainmueller, and Hangartner 2016; Marbach and Ropers 2018). In many countries, extreme-right parties have sought to leverage natives' anxieties to mobilize voters and enact more restrictive asylum policies. Several recent studies that focused on Austria (Steinmayr 2018), France (Vertier and Viskanic 2018), and Greece (Dinas et al. forthcoming) have all corroborated that refugee migration is an important factor fueling the rise of extreme-right parties.

Beyond its impact on aggregate vote shares for extreme-right parties, little is known, however, about how refugee migration shapes the attitudes, policy preferences, and political behavior of European citizens. This lacuna is problematic for our theoretical understanding of the short- and long-term consequences of the refugee crisis on Europe's political landscape and the mechanism under which contact with refugees alleviates or catalyzes concerns. Similarly, policymakers who are tasked with designing a more cooperative asylum system need a deeper understanding of how and when refugee arrivals trigger local opposition and political backlash (Bansak, Hainmueller, and Hangartner 2017).

Why do we know so little about the impact of refugee migration on natives' attitudes, preferences, and behavior? First, in order to go beyond readily available aggregate data on voting behavior and drill down to individual-level outcome measures, one has to field a survey in areas with varying levels of refugee exposure. 


\section{FIGURE 1. Mediterranean Refugee Arrivals}

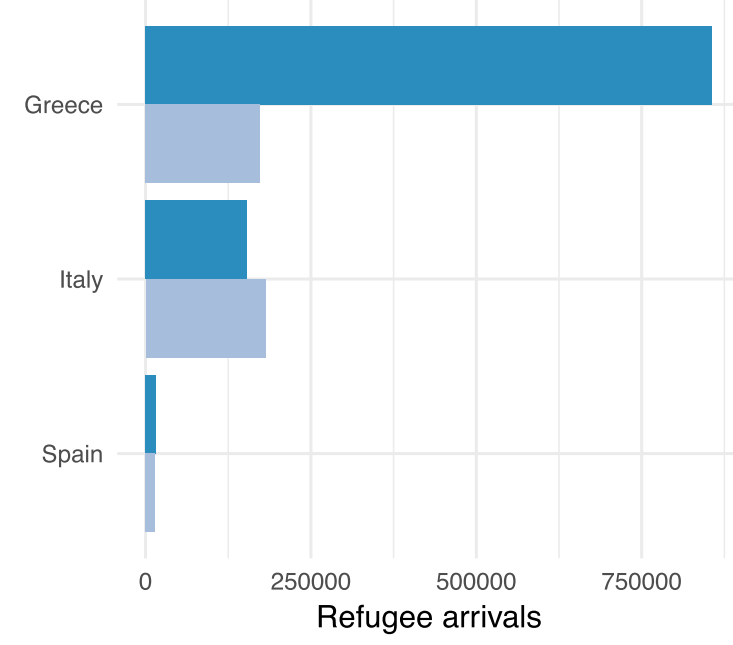

$2015 \quad 2016$

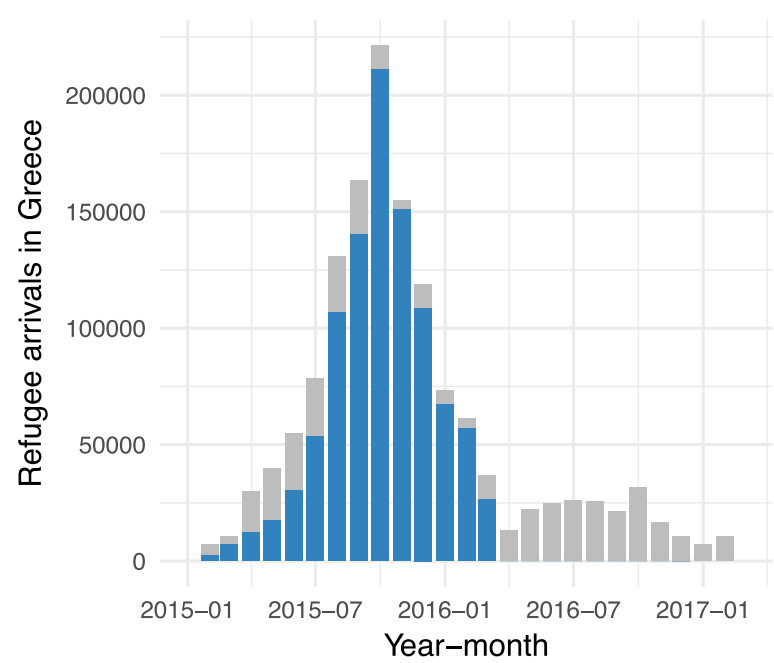

All Greece Islands

Note: Right panel shows the number of sea arrivals across countries at the external border of Europe for 2015 (dark blue) and 2016 (light blue). Left panel shows number of monthly refugee arrivals in all of Greece (gray) and on the Aegean islands (dark blue).

Second, a key problem faced by all studies of the impact of refugee migration is that refugee flows are far from randomly assigned. Starting with Ravenstein's (1885) "law of migration," scholars have explored the migrant's decisionmaking process that determines whether-and where to-migrate, and there is ample evidence that a similar calculus also applies to forcefully displaced people (e.g., Neumayer 2005). Within the financial and legal constraints that asylum seekers face, they tend to flee to places that are feasible to travel to, but also where they are, inter alia, welcome. This latent hospitality toward refugees is hard to measure empirically but will typically confound the relationship between refugee arrivals and outcome measures of hostility (measured after the arrivals took place). If one ignores this important confounder and runs a cross-sectional regression of, say, exclusionary attitudes on refugee arrivals, the estimated correlation might well be negative (indicating that more arrivals alleviate hostility), even if the true causal effect is positive.

In this paper, we address both issues by fielding a targeted survey of European citizens to measure the impact of the refugee crisis on their attitudes toward refugees, immigrants, and Muslim minorities; their preferences regarding asylum, immigration, and integration policies; and their political engagement to enact policies affecting refugees. By focusing the comparison on similar respondents in comparable areas, some of whom were directly exposed to the refugee crisis and some of whom at most indirectly so, we can contribute to the ongoing debate about the consequences of refugee migration and empirically answer the question whether exposure to the refugee crisis triggers or alleviates natives' hostility.

We focus on Greece, one of the European countries most affected by the refugee crisis. With its long coastline along the EU external border, its proximity to the
Turkish coast, and many difficult-to-patrol islands, Greece quickly became the main entry point to Europe for most Syrian and Afghan refugees. Figure 1 (left panel) shows that of the 1.4 million new asylum seekers who have reached European territory between 2015 and 2016 by passing the Mediterranean Sea, more than one million arrived in Greece (UNHCR 2016). Figure 1 (right panel) indicates that in Greece, these arrivals happened within a very short time window: from a baseline of almost zero at the beginning of 2015, the number of monthly arrivals peaked at 211,000 at the height of the crisis in late October 2015. After the March 2016 Agreement between the European Union and Turkey called for the return of refugees arriving in Greece from Turkey, effectively closing off this migration route, arrivals of asylum seekers in Greece immediately decreased to 3,000 per month by the end of 2016 .

These boat arrivals not only took place in a short time window, but were also highly concentrated among about a dozen Greek islands in the Aegean Sea. While islands closest to the Turkish coast received up to five refugee arrivals per resident between the onset of the refugee crisis and the implementation of the EU-Turkey agreement, on islands only slightly farther away the number was essentially zero. As we discuss later in detail, we leverage this distance to the Turkish coast as an instrument for refugee arrivals. This solves the aforementioned selection issue by focusing the analysis on the exogenous part of the variance in refugee arrivals that is solely driven by proximity to Turkey and ignoring the endogenous part that is driven by preexisting differences in attitudes toward refugees.

Several factors facilitate our empirical strategy. First, distance to the Turkish coast causes dramatic variation in the number of refugee arrivals. This allows us to compare 
similar residents on neighboring islands, some of which received hundreds of thousands of passing refugees, while others slightly farther away received none. Second, geographical proximity and the fact that they often belong to the same administrative unit ensures that islands with and without arrivals are identical across many observable and unobservable characteristics, such as the nature and quality of political competition and regional government, provision of public services (education, healthcare, and the judiciary), and access to EU funds. Third, among those islands with refugee arrivals, refugees were concentrated in particular UNHCR hotspots, allowing us to also leverage withinisland variation as a complementary mechanism test.

We find that direct exposure to the refugee crisis has statistically and politically meaningful effects on natives' exclusionary attitudes, preferences over asylum and immigration policies, and political engagement. Exploiting the exogenous variation in refugee arrivals caused by distance to the Turkish coast-our instrument-we find that respondents directly exposed to the refugee crisis experience a $1 / 4$ standard deviation (SD) increase in their anti-asylum seeker and anti-immigrant attitudes as well as a 1/6 SD increase in their anti-Muslim attitudes. Compared to respondents on unexposed islands, they are more likely to oppose hosting additional asylum seekers and to support the ban from school for asylum seekers' children and are less likely to donate to UNHCR and to sign a petition that lobbies the government to provide better housing for refugees. Across all these outcomes, we find that direct exposure to the refugee crisis has a long-term impact on natives' hostility. In a companion study, we also examine the short-term impact of exposure to the refugee crisis on voting behavior in this setting (Dinas et al. forthcoming).

Our study makes four contributions. First, it provides some of the first causal evidence on the impact of the refugee crisis on exclusionary attitudes, policy preferences, and political engagement of European citizens. Second, rather than focusing on contemporaneous, and potentially exacerbated, effects of refugee arrivals, our study allows us to look at the long-term consequences, as we conducted our survey in February and March 2017. Ever since the implementation of the March 2016 Agreement between the European Union and Turkey, refugee flows were minimal, so that our survey measures the persistence of past shocks about a year after the crisis. Third, in Greece, the refugee crisis coincided with economic turmoil and financial austerity imposed by the so-called troika consisting of the European Commission, the European Central Bank, and the IMF, as well as the chaotic management of refugee flows at the local, national, and European level. All these factors are believed to catalyze anti-immigrant sentiment (Dinas et al. forthcoming).

Fourth, to understand how island residents experienced the refugee crisis, it is important to note that almost all refugees left the islands of first arrival within a very short period, typically within twenty-four hours, to continue their journey via Athens to the Greek mainland, and other European countries. The passing presence of refugees on these islands allows us to make important inferences about the drivers of anti-refugee sentiment.
On the one hand, the transient nature of arrivals all but eliminated the chance for sustained interactions between natives and refugees. For contact to reduce tensions, scholars have proposed a fairly strict set of conditions that have to be met, such as friendly acquaintance within a cooperative context (rather than a one-off exchange with a stranger) (Allport 1954; Pettigrew 1998; Van Laar et al. 2005). These conditions were clearly not met in the present context, and our study therefore identifies the "pure" effect of exposure to the refugee crisis. Hence, we have little reason to expect that exposure reduced hostility among the local population.

On the other hand, because refugees quickly left the islands for other European countries, the usual materialist concerns that immigrants compete with natives over scarce resources such as jobs or welfare benefits (Bobo and Hutchings 1996; Scheve and Slaughter 2001) do also not apply in this context. The same is true for ideational concerns that immigrants change the culture and identity of the host country (Golder 2003). Based on these standard theories of the economic and cultural drivers of anti-immigrant sentiment, we would not expect that refugee arrivals trigger exclusionary reactions.

Our finding that hostility prevails in the Greek Aegean islands suggests that mere exposure to the chaos of the refugee crisis generates a feeling of threat that can activate latent predispositions against immigrants and mobilize support for exclusionary policies (Sniderman, Hagendoorn, and Prior 2004). The next section summarizes the predictions of the most prominent theories of intergroup contact and conflict for the present context. After describing the survey sample and measures, the main results, and the mechanism tests, we return to further exploring the implications of our findings for our theoretical understanding of the drivers of exclusionary reactions.

\section{CONTACT, CONFLICT, AND THREAT IN THE CONTEXT OF THE GREEK REFUGEE CRISIS}

A vast literature has investigated how proximity to and contact with immigrants and refugees shape the attitudes of natives. While a full review is beyond the scope of this paper, we focus on the theories and mechanisms most relevant for the context of the refugee crisis and refer the more broadly interested reader to the excellent reviews of Paluck and Green (2009) and Hainmueller and Hopkins (2014).

One stream of research originating from Allport's seminal work (1954) assesses how, and under which conditions, contact between the majority ingroup and an ethnic outgroup can yield increased levels of empathy and understanding (Barlow, Louis, and Hewstone 2009; Berg 2009; Finseraas and Kotsadam 2017; McLaren 2003; Pettigrew and Tropp 2006) and decrease discriminatory behavior (Scacco and Warren 2018). These studies show that if ingroups and outgroups (i) share equal status and common goals, (ii) find themselves in a cooperative rather than competitive environment, and (iii) operate under a well-defined set of norms or regulations, contact can reduce prejudices. And although Allport (1954) was the first to point out that these 
conditions are often hard to meet in reality, contact theory seems to be robust to violations of some of these criteria (Paluck, Green, and Green 2017; Pettigrew and Tropp 2006). Recent works on the mechanism underlying these effects point to the role of contact in increasing knowledge about the outgroup, encouraging perspective taking, and reducing intergroup anxiety (Barlow et al. 2012; Pettigrew and Tropp 2008).

Proximity, however, does not necessarily lead to contact. One example that illustrates this distinction comes from Enos (2014), who randomly assigned physical proximity to outgroup members by placing Spanish-speaking confederates on the Boston subway, without facilitating face-to-face interaction. The result was an increase in exclusionary attitudes among the white-majority group. Observational studies that examine the correlation between the share of immigrants and anti-immigrant sentiment have yielded an ambiguous picture. Whereas some studies suggest that ethnic diversity is accompanied by lower levels of intergroup hostility (Sturgis et al. 2014; Zorlu 2017), others find exactly the opposite (Kaufmann and Harris 2015; Putnam 2007; Schlueter and Scheepers 2010). The latter results are often interpreted as evidence in favor of the realistic group conflict hypothesis: the presence of an outgroup in sufficient numbers generates, according to this line of argument, competition for scarce resources (Blalock 1967; Blumer 1958; Bobo 1983; Bobo and Hutchings 1996; Forbes 1997; Hardin 1997).

Closely related to theories of realistic group conflict is a rapidly increasing stream of political science research that studies the drivers of anti-immigrant sentiment. Numerous explanations have been suggested, yet they tend to cluster into two broad categories: economic concerns and cultural concerns (Golder 2003; Hainmueller and Hopkins 2014). Economic concerns can result from at least three, complementary, sources. Natives can perceive that asylum seekers increase competition in the labor market and thus enhance the risk of unemployment (Mayda 2006; Scheve and Slaughter 2001); alter the means-tested welfare distribution, converting them from net beneficiaries to net contributors (Facchini and Mayda 2009); and lead to congestion effects, defined as the concern that in the short run, supply of public goods and services, such as public housing, health, and education, cannot follow the rapid increase in demand caused by immigration (Cavaille and Ferwerda 2017).

Cultural concerns refer to a more general tendency to perceive outgroup norms and values as incompatible and potentially in conflict with those of the majority ingroup (Brown 2000; Connor 1994). Religious, ethnic, or linguistic differences are often treated as signals of cultural distance, triggering exclusionary preferences as a way of protecting the ingroup's customs and traditions (Bansak, Hainmueller, and Hangartner 2016; Brader, Valentino, and Suhay 2008; Ivarsflaten 2005). Previous research has found that these cultural or identity concerns are often more important for explaining opposition to immigration in Western countries than economic concerns (see, e.g., Hainmueller and Hopkins 2014).

What predictions do these theories make in the context of the Greek refugee crisis? The fact that asylum seekers and refugees quickly passed through the Aegean islands posits a challenge for the contact hypothesis since the conditions under which contact can reduce prejudice are clearly not met in this context. Time for interaction with the same person was minimal, and casual contact did not occur in a cooperative context and happened in the absence of common norms. Furthermore, the potential for friendship was limited since the local population was well aware that refugees are leaving the island with the next available ferry to Athens. ${ }^{1}$

But for the very same reason, we would also not expect that economic and cultural concerns play a major role in this context. Refugees did not enter the labor market on these islands and did not request welfare benefits or apply for public housing. The accommodation costs of the refugee camps, where a few of the refugees stayed for a while before continuing their journey, were mostly shouldered by the central government and the European Union. For the same reason, perceptions of threat to national identity should also be minimal, as it soon became obvious that virtually all asylum seekers would quickly leave the islands. Accordingly, standard theories of cultural and economic concerns would predict that passing migration flows do not trigger a lasting increase in anti-immigration sentiment.

The massive numbers of refugee arrivals, albeit transient in nature did, however, clearly disrupt the daily life and routines of the native island population. Numerous reports in the local press highlight the inability of the local and national authorities to effectively provide medical support, ${ }^{2}$ sanitary services,${ }^{3}$ and waste collection ${ }^{4}$ for the passing refugees. Mountains of rubbish and open defecation surrounding arrival and departure hotspots sparked concerns about the spread of diseases. Chaotic scenes and the presence of large number of staff and volunteers from the UNHCR, the EU, the National Center of Disease Control and Prevention, and various NGOs further compounded these effects to create the impression of a state of emergency. In fact, the mayor of Lesvos, Spyros Galinos, asked the central government to declare a state of emergency akin to that following major natural disasters. He wrote in his (open) letter to the central government: "the whole

\footnotetext{
${ }^{1}$ A fraction, about 11,000 of the more than one million asylum seekers that arrived on the Aegean islands, is still hosted in refugee camps on a few islands. These refugee camps, the largest of which is Lesvos' Moria, are, however, located in the rural countryside, which severely limits the potential for interaction. Furthermore, as the robustness tests in Appendix E9 show, our results are robust to excluding respondents in the proximity of these camps.

${ }^{2}$ See, e.g., the editorial "The State is late but... volunteers and the municipality are rushing [to respond to the crisis]" (author translation) in the newspaper Empros on September 5, 2015. http://www. emprosnet.gr/koinonia/75136-kratos-argei-alla-ethelontes-kaidimos-trehoyn.

${ }^{3}$ See, e.g., the editorial "Social Explosion is in sight" (author translation) in the newspaper Dimokratis on September 3, 2015. www. dimokratis.gr/index.php? article $=2015-9-3$ _orati_i_koinoniki_ekrixi.

${ }^{4}$ See, e.g., Marinos Orfanos in the newspaper Empros: "The port [of Mytilene] has become a vast dumpster bin and a space of open-air toilets" (author translation) on September 2, 2015. http://www. emprosnet.gr/koinonia/75750-zamtrakis-aperanti-homateri-kai-horosypaithrion-afodeytirion-limani.
} 
situation and the inability [of the central administration] to handle it leaves local communities at the verge of social explosion [...] the non-controlled nature of the refugee crisis has already turned this problem into a threat that is proportionate to a large scale natural disaster $[\ldots]$ the rule of law needs to be reinstated [...], public health needs to be safeguarded and the social order of the island needs to be maintained, and the migrants need to be treated humanely according to the provisions of the UN Charter for human rights." 5

The mayor's letter and the newspaper reports make clear that this disruption of everyday life was not a mere nuisance for the local population, but was perceived as an upset of the social order and generated a feeling of threat. Recent work on social threat suggests that the perception of a threatening environment can activate otherwise latent predispositions against immigrants and other minorities (Feldman and Stenner 1997; Hetherington and Weiler 2009; Stenner 2005). This process can have two complementary consequences: first, the chaos on arrival islands might act as a situational trigger that "galvanizes" (Sniderman, Hagendoorn, and Prior 2004) the attitudes of those already predisposed against immigration. Second, perceived threat and anxiety might also mobilize support for exclusionary policies above and beyond those that already hold hostile attitudes (Brader, Valentino, and Suhay 2008; Sniderman, Hagendoorn, and Prior 2004). Since perceptions of threat and anxiety are emotional triggers, they make it likely that individuals will not only change their attitudes or beliefs, but also take political action (Brader 2006; Brader, Valentino, and Suhay 2008).

Furthermore, the referenced newspaper articles suggest that perceived levels of social threat were highest in the vicinity of the arrival and departure hotspots. In the locations where refugees gathered, the failure of the Greek government and the European Union in managing the refugee flows was most visible, and their disruption of natives' everyday life most severe. Hence, akin to Hopkins' (2010) politicized places hypothesis, we expect to find the strongest increases in outgroup hostility for natives living in close proximity of the hotspots that experienced the refugee crisis most intensely.

Taken together, these factors suggest that social threat can explain how the chaotic management of refugee flows activates exclusionary reactions to immigrants and ethnic minorities, even in a context where these flows are temporary and transient. In the absence of contact, as well as economic or cultural concerns, the mere exposure to the refugee crisis suffices to crystallize latent anti-immigrant attitudes and mobilize citizens to support exclusionary policies.

\section{EMPIRICAL STRATEGY}

To estimate the causal effect of exposure to the refugee crisis on natives' exclusionary attitudes, policy preferences, and political engagement, we leverage the

\footnotetext{
${ }^{5}$ A copy of the letter is available here: https://tinyurl.com/yc4ruefh.
}

distance of an island to the Turkish coast as an instrument for refugee arrivals. This instrumental variable approach allows us to resolve the selection bias associated with refugees choosing their arrival island based on preexisting levels of hostility toward outgroups.

As shown in Figure 2, islands very close to the Turkish coast, such as Samos, Chios, and Lesvos, received more than five arrivals per island resident within the 14 months between the onset of the crisis in early 2015 and implementation of the EU-Turkey agreement in March 2016. The number of arrivals rapidly decreases as the distance to Turkey increases, with islands farther than 50 kilometer away not registering any refugees. As indicated by the blue line, the relationship between per capita refugee arrivals and logged distance can be well approximated using linear regression. Table D10 in Appendix provides the estimates from these first-stage regressions of the per capita number of arrivals on distance and a binary indicator of arrivals on distance, respectively. The first stage for the binary treatment, our main specification, is very strong $(F$-statistic $=133.75)$. The reason for this becomes clear in Figure 2: while all but two islands that are less than 50 kilometers away from Turkey receive refugees, no island more than 50 kilometers away register any arrivals. As robustness tests, we also estimate the first stage using a continuous measure of the number of arrivals per capita and the log number of arrivals per capita. ${ }^{6}$ The corresponding $F$ statistics are 9.22 and 14.20 , respectively, around the critical value proposed by Stock and Yogo (2002).

One frequent concern with instrumental variable analysis is the credibility of the exclusion restriction. In our context, a violation of the exclusion restriction would mean that islands slightly farther away from the Turkish coast not only register fewer refugee arrivals, but are also different in other, preexisting, characteristics such as the sociodemographic composition or political preferences of the local population. Fortunately, we can conduct a variety of placebo tests that show that this is not a concern. Table 1 provides the estimates from two-stage least squares regressions, our main specification further discussed below, of the placebo outcomes on a binary indicator for refugee arrivals, instrumented with distance to the Turkish coast. For all placebo outcomes - vote choice for the main parties Golden Dawn, Nea Dimokratia, and $P A S O K$ in the January 2015 election (prior to the onset of the refugee crisis) and the demographic indicators for female, old versus young (split at the median age), and tertiary education - we find no significant effect. Table D11 in Appendix extends the analysis to smaller parties that also ran in the January 2015 elections and a linear specification for education and age. None of the estimated coefficients is significantly different from zero, thereby supporting our confidence in the validity of the instrument.

\footnotetext{
${ }^{6}$ We are grateful to an anonymous reviewer for pointing us to the log$\log$ specification. Hence, this robustness test was not prespecified in the pre-analysis plan.
} 


\section{FIGURE 2. Visualization of the First-Stage Estimates}

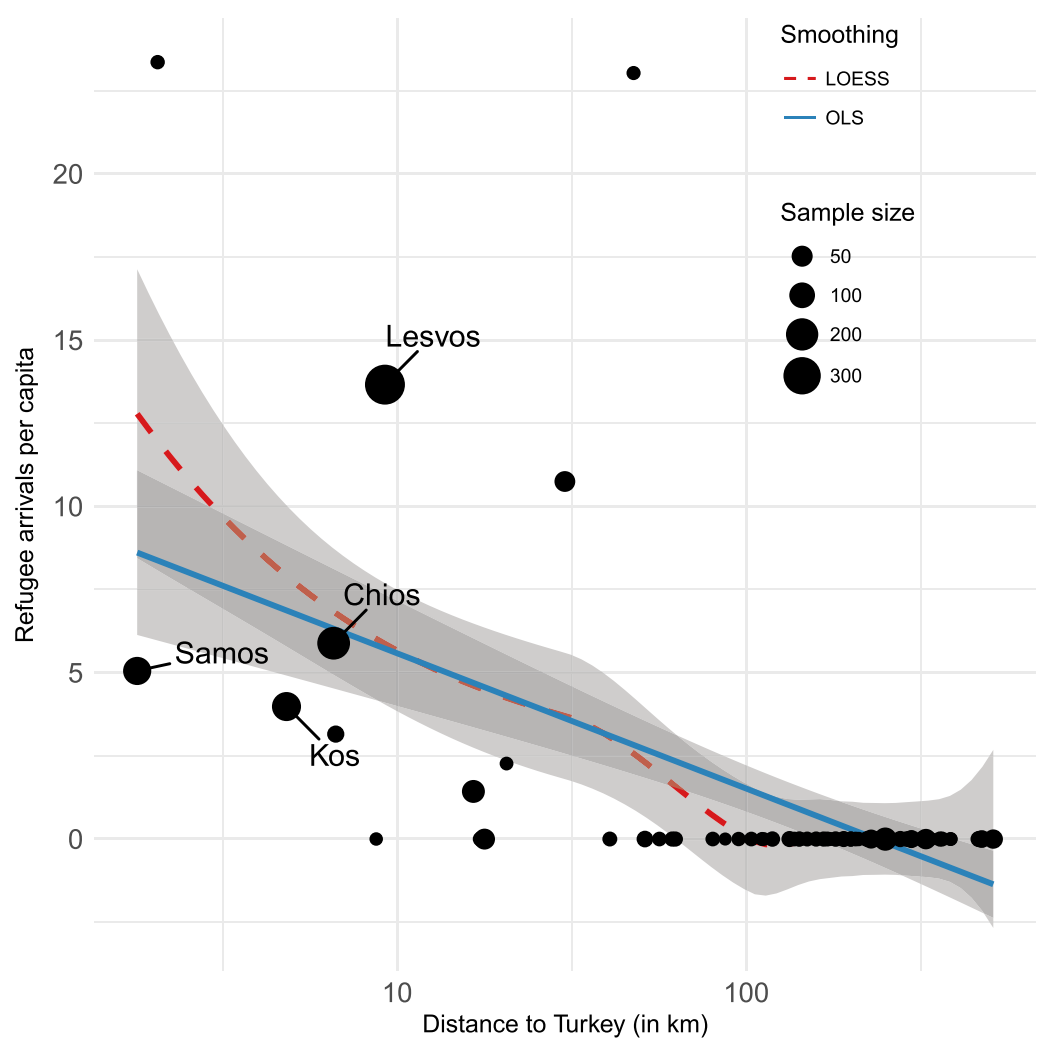

Note: The blue line indicates the OLS regression of the cumulative number of refugee arrivals per island resident on the logged distance to the Turkish coast. The red line shows the analogous scatterplot smoother. The size of the dots is proportional to the number of survey respondents.

\section{TABLE 1. Placebo Outcomes}

\begin{tabular}{lccccccc}
\hline & GD & S/A & ND & PASOK & Female & Age & Education \\
\hline Treatment & 0.00 & -0.06 & 0.04 & 0.02 & -0.03 & -0.01 & -0.03 \\
Constant & $(0.008)$ & $(0.029)$ & $(0.024)$ & $(0.013)$ & $(0.030)$ & $(0.032)$ & $(0.024)$ \\
$N$ & $0.02^{\star \star \star}$ & $0.39^{\star \star \star}$ & $0.21^{\star \star \star}$ & $0.07^{\star \star \star}$ & $0.57^{\star \star \star}$ & $0.50^{\star \star \star}$ & $0.47^{\star \star \star}$ \\
$N$ & $(0.006)$ & $(0.021)$ & $(0.020)$ & $(0.010)$ & $(0.021)$ & $(0.024)$ & $(0.020)$ \\
& 2,046 & 2,046 & 2,046 & 2,046 & 2,046 & 2,046 & 2,046 \\
\hline
\end{tabular}

Note: $2 S L S$ regression estimates (with cluster-robust standard errors in parentheses) of placebo outcomes of refugee arrivals, instrumented with the island's distance to the Turkish coast. Outcomes are vote choice for: Golden Dawn (GD), SYRIZA/ANEL (S/A), Nea Dimokratia (ND), and PASOK in the January 2015 election; demographic indicators for female, older than median age of 50 , and tertiary education. ${ }^{\star} p<0.05 ;{ }^{* *} p<0.01 ;{ }^{* *} p<0.001$.

\section{SURVEY}

In order to assess the impact of refugee arrivals in the Aegean Sea, our sampling frame consists of all inhabited Greek islands. Between February 22 and March 7, 2017, we successfully interviewed 2,070 respondents, split equally between treated and control islands and proportional to the population of each island. All interviews were conducted using computerassisted telephone interview (CATI) by calling landline numbers, which were randomly selected from the telephone registry. ${ }^{7}$ Within each household, the respondent was selected using the next-birthday method, an efficient procedure for selecting a sample that is representative of

\footnotetext{
${ }^{7}$ The survey was fielded by the Survey Unit of the University of Macedonia according to our sampling frame and in line with the ethics policy of the London School of Economics and Political Science for human subjects research.
} 
all household members (Salmon and Nichols 1983). The cumulative response rate (RR3) as defined by the American Association for Public Opinion Research is $8 \%$, which is about the same as the response rate for CATI interviews in the USA (Keeter et al. 2017). One potential concern is that the willingness to be interviewed is correlated with distance to the Turkish coast, which might confound the analysis. However, this is not the case: the probability of being interviewed is very similar for residents living close and farther away from the Turkish coast, and Welch's $t$-test cannot reject the null hypothesis of no difference at conventional levels $(p>$ 0.094, two-tailed).

The main analysis using all adult respondents presented below uses survey weights that are proportional to the population size of the island under the constraint that the respondents of treated and control islands receive half of the aggregate weight each. Item nonresponse was generally low (on average $4.9 \%$ across all measures) but in order to remove any imbalances and increase the efficiency of our estimates, we use multiple imputation to address missing answers. The robustness section below shows that all results also hold with alternative weighting strategies, without weighting, and list-wise deletion. Further details on the sampling frame, survey weights, and multiple imputation are provided in Appendix Section A.

\section{Outcome Measures}

For the outcomes, we employ standard indicators for attitudes toward outgroup minorities, policy preferences concerning refugee and voluntary migration, and quasi-behavioral measures of political engagement. We use a series of feeling thermometer questions about various outgroups (relative to the majority group) as explicit measures of racial attitudes. Past research has shown that they are highly correlated with behavioral measures of discrimination (McConnell and Leibold 2001). The additional attitudinal questions are largely based on the Global Attitudes Survey (Wike, Stokes, and Simmons 2016), but answers are recorded on a fivepoint scale to decrease acquiescence response bias (Revilla, Saris, and Krosnick 2014). The questions eliciting policy preferences are adapted from Bansak, Hainmueller, and Hangartner (2017) and tailored toward the Greek case. Lastly, the quasi-behavioral outcomes attach real-life consequences to the respondents' answers to questions about political preferences and engagement in the refugee context (Brader, Valentino, and Suhay 2008).

The first set of outcomes measures anti-asylum seeker policy preferences and attitudes. We asked respondents whether they agreed that refugee children should be banned from schools (from 1 to 5), an issue that was hotly debated at the time of the survey; that Greece should decrease the number of people to whom it grants asylum (1-5); and that asylum seekers are more likely to commit terrorist attacks (1-5) and crimes (1-5) and are a burden on the country (1-5).

The second set of outcomes measures more general anti-immigrant policy preferences and attitudes. We asked respondents if they support a decrease in the number of economic migrants (from 1 to 5 ) and stronger border protection (1-5). We also measured the difference in their feeling thermometer scores (0-100) between Greek Muslims and Muslim immigrants, and Greek Christians and Christian immigrants.

The third set of outcomes provides quasi-behavioral measures of respondents' willingness to politically engage to change asylum policies and donate to support refugees. We asked respondents whether we should notify their Member of Parliament (MP) on their behalf that they support a decrease (or increase) of the number of people to whom Greece grants asylum (from 1 to 5); whether $(0 / 1)$ and how much $(0-100)$ they wanted to donate to UNHCR if they won the EUR 100 raffle that was part of the survey; and whether they would like to sign an existing petition that lobbies the government to provide better housing for refugees $(0 / 1)$.

The fourth set of outcomes measures general antiMuslim policy preferences and attitudes. We asked respondents whether they believed that the political representation of the Greek Muslim minority in the Greek parliament should be reduced, remain the same, or be increased (1-5). We also measured the difference in their feeling thermometer scores (0-100) between Christian immigrants and Muslim immigrants and asked whether they believe that most Muslims are not willing to integrate (1-5) and are likely to support extremist groups (1-5). ${ }^{8}$ The question wording and outcome coding are reported in Appendix Section A.3 and A.4.

Lastly, for each of the four sets of outcomes, we built a summary scale that combines the different measures by extracting the first component of a polychoric principal component analysis (PCA) (Olsson 1979). Appendix Section A. 3 provides details on the PCA and shows that for each scale, the first component explains a large share of the total variance. Averaging responses across multiple items measuring the same latent construct not only reduces bias and variance from random measurement error that is common in survey research (Hainmueller, Hangartner, and Pietrantuono 2017), but also alleviates worries about false-positive significance tests by focusing the analysis on a few main outcomes.

\section{Treatment and Instrument}

To measure refugee arrival, our treatment variable, we use island-level registry data collected by UNHCR (2016). Figure 3 shows the strong clustering of arrivals on islands close to the Turkish coast. We code a binary indicator equal to one if UNHCR recorded a positive number of arrivals and 0 otherwise. As robustness tests, we also code two continuous measures based on the cumulative number of arrivals between January 2015 and March 2016 as a fraction of the number of island residents and the $\log (+1)$ of this ratio, respectively.

\footnotetext{
${ }^{8}$ We also included a battery of questions that measure general attitudes toward outgroups with questions such as: "For being truly Greek, it is important to (i) have been born in Greece; (ii) being able to speak Greek; (iii) being Christian Orthodox." We do not find any effect of refugee arrivals on these outcomes. The results are shown in Appendix Section D.
} 


\section{FIGURE 3. Map of the Aegean Sea}

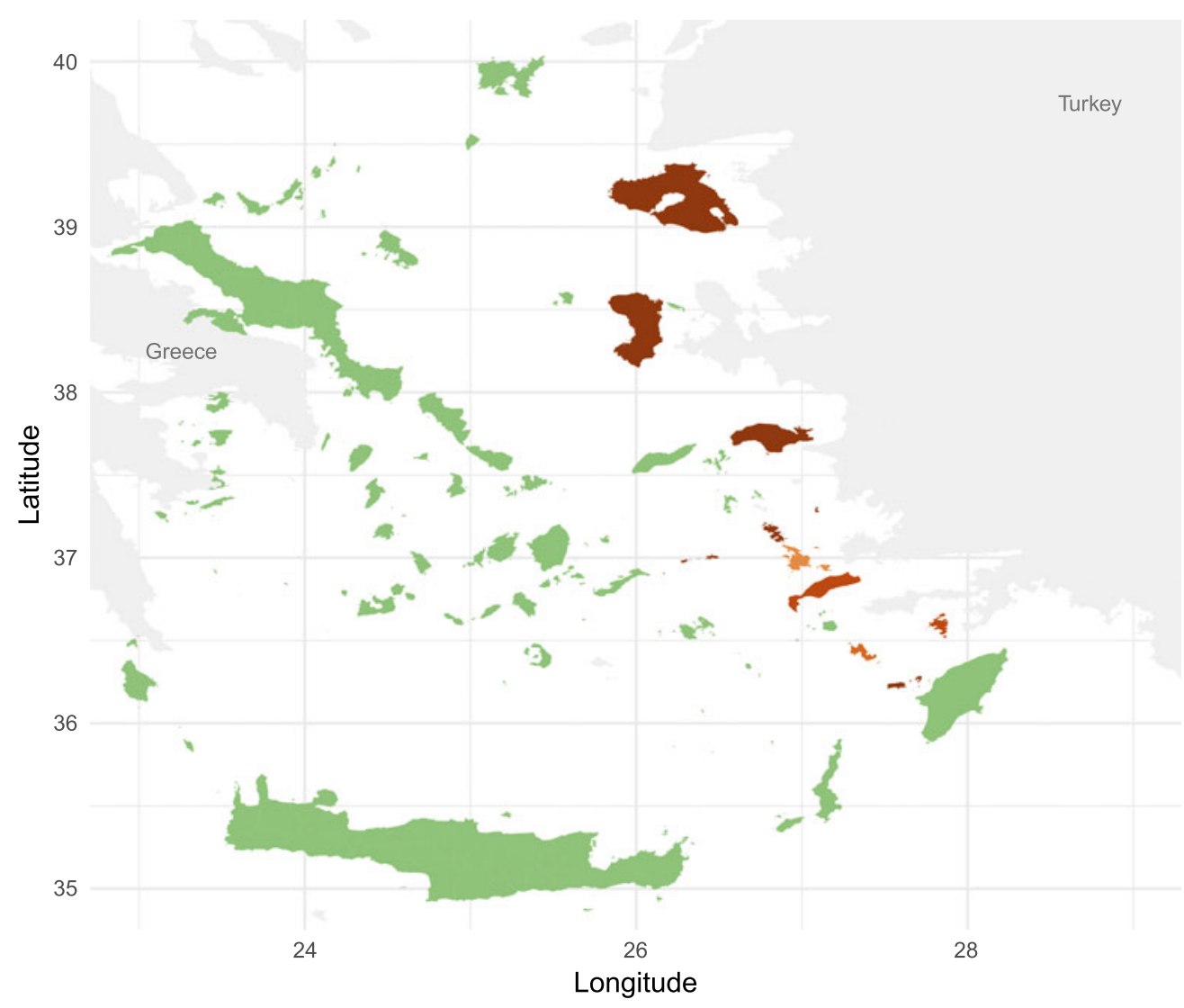

Refugee arrivals per capita

\begin{tabular}{ll|l|l|l|l|} 
not in sample & 0 & $(0,1]$ & $(1,2]$ & $(2,3]$ & $(3,4]$
\end{tabular}$\quad>4$

Our instrument is the logarithm of the shortest path (henceforth distance) between Turkish coast and the population center of a municipality (typically an island), which we calculate using Google Maps. This distance measure correlates highly $(r=0.997)$ with an alternative distance measure based on the polygon's centroid of a municipality in Greece and the closest point to the Turkish polygon in GIS software.

\section{Statistical Analysis}

To estimate the effect of exposure to the refugee crisis, we fit two-stage least squares (2SLS) models in which we regress the outcome on our binary exposure indicator controlling for respondent demographic characteristics. We instrument the exposure dummy with a continuous instrument as described above. For all analyses, we cluster standard errors by municipality, of which there are 92 in our main specification. The standard errors are virtually identical if we cluster at the island level (see Appendix Figure E7).

The sampling frame, questionnaire, coding rules for covariates and outcomes (including the summary scales extracted from the PCA), and statistical analyses were all prespecified in a pre-analysis plan posted to the Political Science Registered Studies Dataverse before we conducted the survey and can be retrieved at doi: 10.7910/DVN/FFEUEH.

\section{RESULTS}

In Figure 4, we present the effect estimates for the instrumented treatment. Tables D4-D9 in Appendix report the full regression tables. The black estimates show the impact of exposure to the refugee crisis on the first principal components for each summary measure. Exploiting exogenous variation in refugee arrivals, we find that respondents on directly exposed islands experience an increase of about 0.24 SD in their hostility toward asylum seekers $(p<0.001$, twotailed), $0.23 \mathrm{SD}$ in their hostility toward immigrants ( $p$ $=0.001)$, and $0.13 \mathrm{SD}$ in their hostility toward Muslims $(p=0.041)$. Finally, we find that immediate exposure has a strong impact on our summary measure of the quasi-behavioral outcomes and increases anti-refugee political engagement by 0.33 $\mathrm{SD}(p<0.001)$. 


\section{FIGURE 4. 2SLS Regression Estimates of the Impact of Refugee Arrivals}

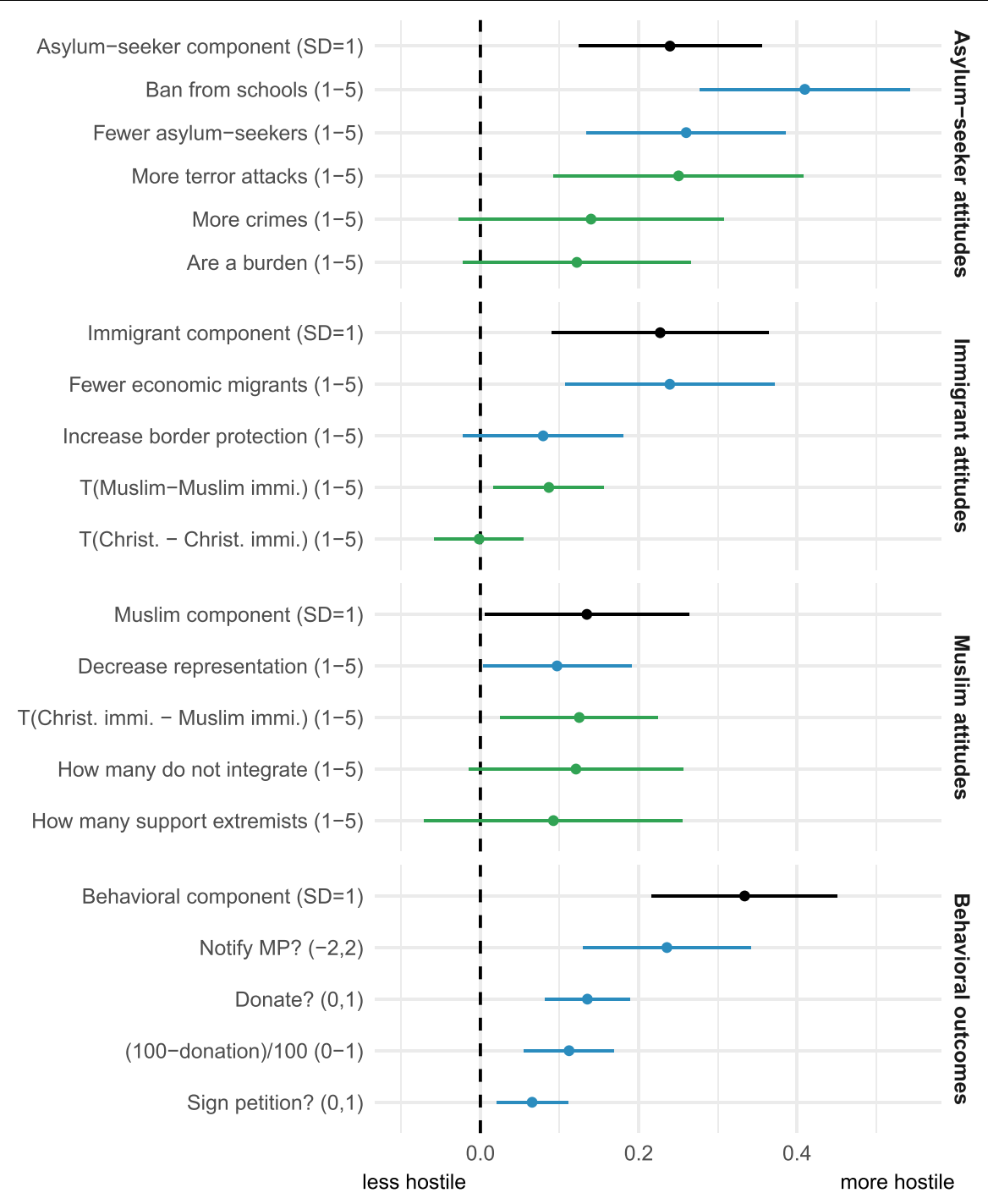

Note: 2SLS regression estimates (with $95 \%$ confidence intervals based on cluster-robust standard errors) of the impact of refugee arrivals, instrumented with the island's distance to the Turkish coast, on respondents' attitudes (green), policy preferences (blue), and PCA-based summary measure (black).

Looking at the outcomes separately, we see consistent changes in policy preferences (blue estimates) and attitudes (green estimates) and that the former are generally larger. With regard to anti-asylum seeker preferences, we find that respondents on exposed islands are more likely to support banning refugee children from schools (point estimate: 0.41 units on a five point scale, $p<0.001$ ) and decreasing the number of people to whom Greece grants asylum $(0.26, p<0.001)$. These policy preferences are particularly remarkable because refugees only passed through the islands and were not sending their children to Aegean schools. We also find that exposure to the refugee crisis leads to an increase in anti-asylum seeker attitudes: exposed respondents believe that asylum seekers are more likely to commit terrorist attacks $(0.25, p=0.002)$ and crimes $(0.14, p=0.102)$ and are a burden on Greece $(0.12, p=0.097)$.
With regard to general anti-immigrant policy preferences, we find that respondents on exposed islands prefer fewer economic migrants $(0.24, p<0.001)$ and stronger border protection $(0.08, p=0.0126)$. Turning to the feeling thermometer scores, we see that exposed respondents prefer Greek Muslims over Muslim immigrants $(0.09, p=0.015)$ but find no effect on the difference between Christian Greek natives and Christian immigrants $(-0.002, p=0.956)$.

Looking at anti-Muslim policy preferences, we find that exposure to the refugee crisis significantly weakens support for the political representation of the Muslim minority in the Greek parliament $(0.10, p=0.043)$. This effect on domestic policy is remarkable as Greece has had a sizable Muslim minority since the Ottoman Empire, and the issue of adequate parliamentary representation of Greek Muslims is unrelated to the 
refugee issue. While respondents on arrival islands more strongly prefer Christian over Muslim immigrants $(0.12, p=0.014)$, we do not find any differences in respondents' beliefs about the willingness of Muslims living in Greece to adopt Greek culture $(0.12, p=0.081)$ or support extremist groups $(0.09, p=0.271)$.

Turning to the quasi-behavioral outcomes, we find that exposure to the refugee crisis increases political engagement in support of more restrictive asylum policies. Confirming the results based on stated preferences discussed above, residents on exposed islands are more likely to lobby their MP to grant fewer asylum requests $(0.24$ unit increase on five point scale, $p<$ $0.001)$. They are also 14 percentage points less likely to donate to the UNHCR $(p<0.001)$ and donate on average EUR 11 less $(p<0.001)$. Lastly, these residents are 7 percentage points less likely to sign a petition that lobbies the national Greek government to provide better accommodation for asylum seekers $(p=0.005)$.

Most of these effects are not only statistically significant but also politically important. To benchmark the results, we can compare the effect size for the outcome that measures support for decreasing the number of granted asylum requests to a recently conducted survey covering fifteen European countries (Bansak, Hainmueller, and Hangartner 2016) that asked the same question. Appendix Figure D1 shows that the 0.26 unit increase resulting from direct exposure to the refugee crisis is about equivalent to moving from the second most liberal (Norway) to the second most restrictive country (Hungary) of the fifteen surveyed countries.

\section{Robustness}

One concern is that there might be unobserved characteristics that differ between islands closer and farther away from the Turkish coast that are also correlated with preferences over asylum policies, thereby invalidating the ignorability assumption for our instrument. We conduct a series of tests to show that this concern is unwarranted.

First, we control for respondents' vote choice in the last election prior to the refugee crisis in January 2015. With the presence of the fiercely anti-immigrant Golden Dawn, we can expect that support for different parties is correlated with anti-immigrant and refugee attitudes and therefore a good proxy for preexisting differences among islands that are closer and farther away from Turkey. Figure E2 in Appendix shows that this concern is unfounded. Adding binary indicators for voting for one of the parties running for office (plus abstention) as covariates has little effect on our estimates. These null effects further corroborate the validity of the exclusion restriction discussed in the previous section. Alternatively, we can also use municipal-level vote shares from the January 2015 election to adjust for preexisting differences in political preferences. Appendix Figure E3 shows that all results remain unchanged.

As a second check, we constrain the sample to islands that are relatively close to the Turkish border. If there is an unobserved confounder correlated with distance, the effect estimates for the subsample of islands within a 255-kilometer (the midpoint of our distance variable) perimeter of Turkey should be different from the estimates from the full sample. Figure E4 in Appendix shows that this is not the case and that the subsample estimates are very similar.

Third, we re-estimate all IV regressions but use the continuous measures of refugee arrivals per island residents instead of the binary indicator. Figure E5 in Appendix shows the results, which follow the same pattern that we have observed for the binary arrival indicator. This finding not only confirms the robustness of our main results, but also reveals that the intensity of arrivals, i.e., the intensive margin, matters. While the binary estimates show that the arrival of refugees triggers hostile reactions among natives, the continuous treatment estimates indicate that their relative number also matters: for 10 additional refugee arrivals per resident, the anti-refugee, anti-immigrant, and antiMuslim preferences increase by $0.31 \mathrm{SD}(p<0.001)$, $0.29 \mathrm{SD}(p<0.001)$, and $0.17 \mathrm{SD}(p=0.008)$, respectively. The results for log arrivals are very similar, in terms of both effect size and significance.

Lastly, in order to gauge the impact of the weighting and multiple imputation procedure on the results, we estimate our main regression with weights proportional to the number of voters of the island (independent of treatment status); with weights provided by the survey company balancing the sample by gender, age, and population density; with equal weights per respondent; and with and without multiple imputation. As Figure E6 in Appendix shows, all estimates remain robust to those alternative specifications.

\section{Mechanisms}

This section explores different mechanisms that predict when, and for whom, exposure to the refugee crisis triggers exclusionary reactions. First, we consider whether respondents who receive their income primarily from tourism react more strongly to refugee arrivals, due to material concerns about the impact on their revenue. To test for this mechanism, we replicate the main analysis but subset the sample to respondents whose income stems exclusively, partially, or not at all from tourism. Figure E11 in Appendix shows the results. While there is some heterogeneity in treatment effects for respondents depending on their main source of income, there is no consistent pattern and most of these differences are not statistically significant. This finding further supports the argument that not egocentric economic concerns, but rather the chaotic management of the refugee crisis, triggered hostility among the local population.

Second, we test whether the impact of the refugee crisis is strongest in the vicinity of the hotspots, where perceived threat arguably reached its highest levels. To answer this question, we leverage a complementary empirical strategy that focuses on islands that registered arrivals and exploit the within-island variation of the distance between respondents' township and the closest refugee hotspot. As hotspots, we code (UNHCR) refugee camps and the ports from which refugees continued their journeys via ferries to Athens and beyond. Figure 5 shows a map of these hotspots. 


\section{FIGURE 5. Location of Hotspots Based on Data From the UNHCR}

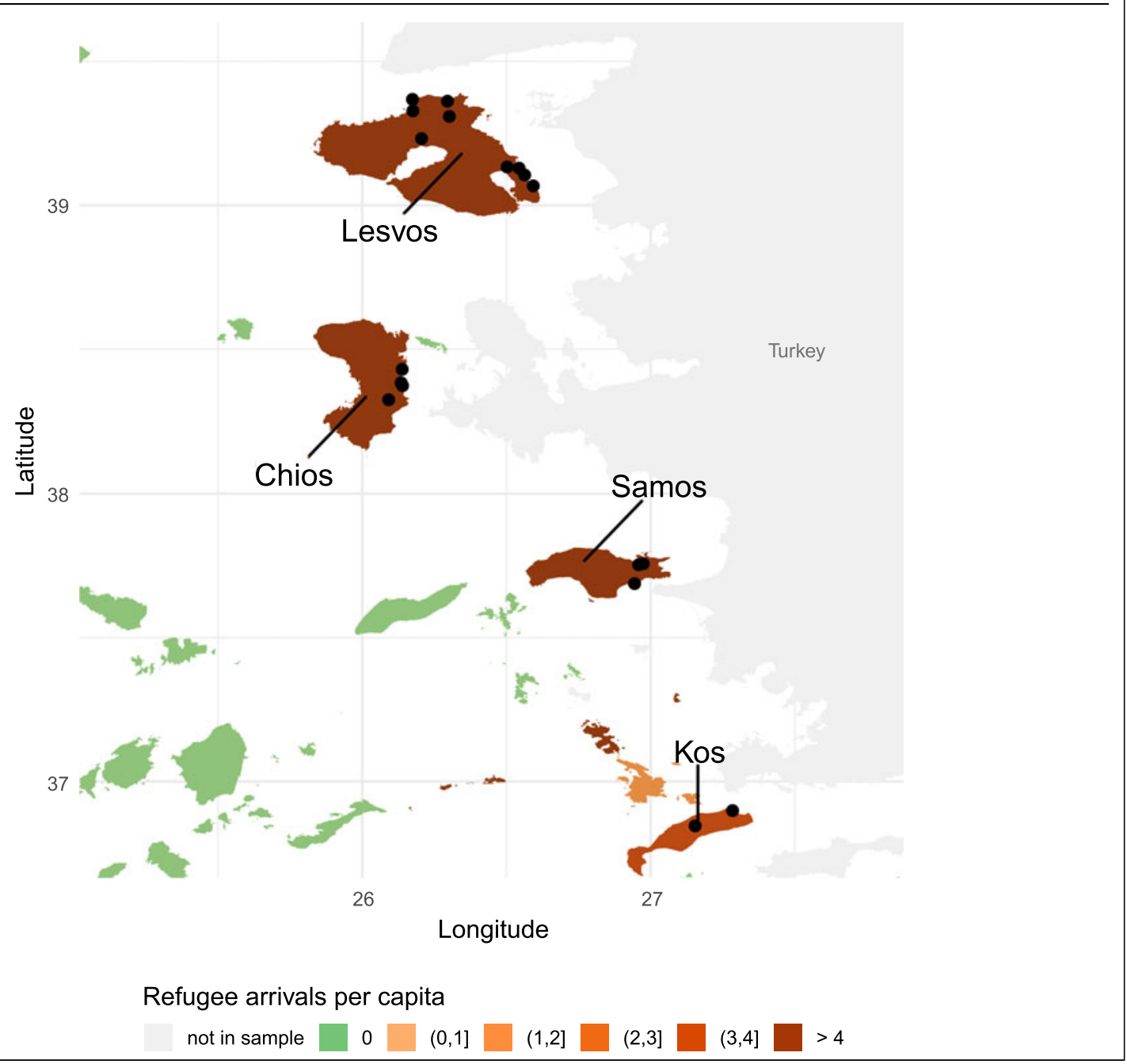

Figure 6 presents the results from the within-island analysis. We run a series of OLS regressions with fixed effects for each municipality, where we use the same outcomes but respondents' distance to the hotspot as the treatment variable. We specify three different functions for the treatment: a binary indicator for living within a 10-kilometer radius of a hotspot, a continuous measure of distance in kilometers, and logged distance.

Despite the difference in the empirical strategy and the focus on highly local variation in exposure to the refugee crisis, where spillover effects on island residents slightly farther away are likely, the findings are remarkably similar to our main estimates identified from between-island variation. Proximity to refugee hotspots significantly and substantially increases respondents' hostility toward asylum seekers and economic immigrants and also increases their support for exclusionary policies. This pattern is consistent with the idea that the highly localized and spatially concentrated chaos surrounding the hotspots created a feeling of threat and triggered exclusionary reactions among natives.

A third mechanism relevant for our theoretical understanding of the drivers of anti-immigrant attitudes concerns "galvanization effects" (Sniderman, Hagendoorn, and Prior 2004), i.e., the idea that situational triggers disproportionally affect the reactions of those who are already predisposed to feeling threatened. If so, we would expect that those with the highest level of preexisting anti-immigrant preferences are most strongly affected by the perceived threat induced by the refugee crisis (Hetherington and Weiler 2009). Alternatively, we might believe that instead of further hardening the attitudes of already hostile citizens, threat might induce citizens with relatively positive attitudes toward outgroups and, absent the crisis, low levels of threat, becoming more hostile (Stenner 2005).

In order to discriminate between these two competing hypotheses, we run a series of quantile instrumental variable regressions (Chernozhukov and Hansen 2005), which enable us to estimate the treatment effect at different deciles of the outcome distribution. Figure E10 in Appendix presents the effect estimates for the four principal components. The general pattern is that the treatment effects are fairly constant across the different deciles, meaning that those with less exclusionary attitudes react similarly negative 


\section{FIGURE 6. Within-Island OLS Estimates (with $95 \%$ Confidence Intervals Based on Cluster-Robust Standard Errors) of the Effect of Distance to the Hotspot on Natives' Attitudes}

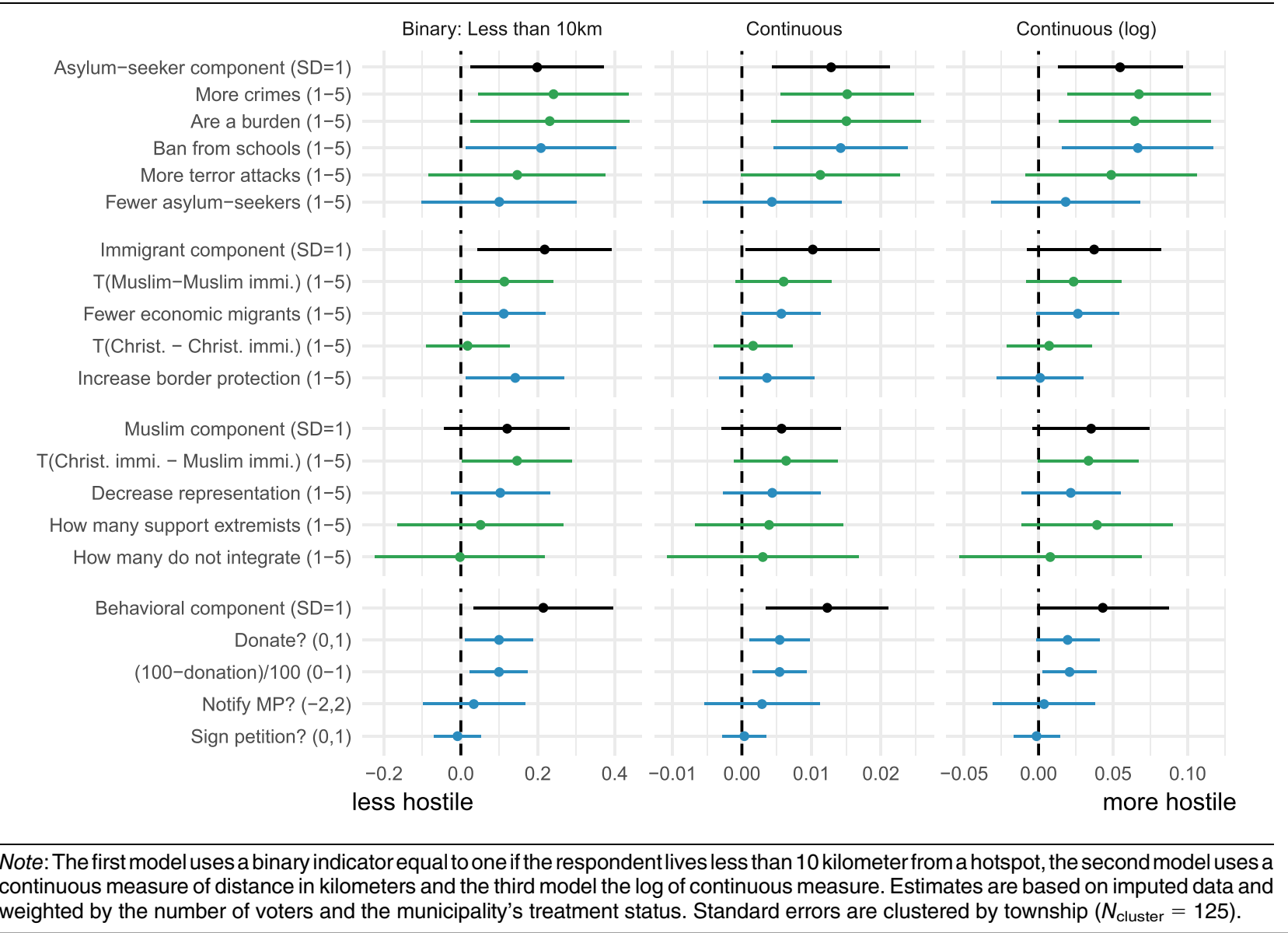

to the refugee crisis as those with already strong exclusionary attitudes. While some of the estimates are slightly larger for respondents with more hostile views, these differences are not always statistically significant.

We also perform an additional test that splits the sample into voters who supported either right-wing (New Democracy) or extreme-right (Golden Dawn) parties versus not voting for one of these two parties in January 2015, the last pretreatment election. If the impact of the crisis amplifies partisan differences, we would expect that the effect is more pronounced among right-wing or extreme-right voters (Gravelle 2016, 2018). If, however, exposure mutes partisan differences, we would expect larger effects among voters for leftist and centrist parties (Branton et al. 2007). ${ }^{9}$ Figure E8 in Appendix shows again that the effects are fairly similar between right-wing/extreme-right and centrist/leftist voters. A Welch's $t$-test indicates that for all four components, the differences between the subgroups are

\footnotetext{
${ }^{9}$ This test was suggested by an anonymous reviewer and was not specified in the pre-analysis plan. The complement to voting for the New Democracy or Golden Dawn is voting for SYRIZA, ANEL, PASOK, KKE, ANTARSYA, The River, Democrats' and Socialists' Movement, $E K$, any other party not listed in the survey questionnaire, and people who did not vote.
}

not statistically significant $(p=0.270, p=0.261, p=$ $0.639, p=0.981)$. Together, the two analyses seem to provide little evidence for either hypothesis, suggesting instead that the exposure effects spread quite uniformly across the ideological spectrum.

\section{CONCLUSION}

This study exploits a natural experiment in the Aegean Sea to examine the impact of the refugee crisis on the attitudes, policy preferences, and political engagement of natives. Using distance to the Turkish coast as an instrument for exposure to the refugee crisis, we find that residents of islands that experience large and sudden influxes of refugees become more hostile toward asylum seekers, immigrants, and Muslims, and are more likely to support and lobby for more restrictive asylum policies than natives in similar islands that receive fewer or no asylum seekers. Substituting the binary with a continuous arrival measure, we find that exposure to the refugee crisis impacts attitudes at both extensive and intensive margins, i.e., that natives' hostility to refugee and immigrant outgroups grows proportionally to the number of arrivals. These findings are further supported by 
complementary within-island analyses, which reveal that most of the political backlash against refugee arrivals is spatially concentrated. These effects are large enough to be politically significant. For example, with respect to the question of whether the government should decrease the number of people to whom it grants asylum, the differences in opinion among Greek residents on exposed and nonexposed islands are as big as the differences in opinion among citizens of very restrictive and very liberal countries in Europe.

While the massive refugee arrival on Greek islands is an extreme case, people in many places have been exposed to past and ongoing refugee crises in similar ways. Since refugees, unlike other migrants, rarely have the ability to travel by plane, they typically pass through several countries until they reach their destination. For example, in the context of the current refugee crisis, millions of citizens from transit countries observed Afghan and Syrian refugees traveling to Western Europe via Jordan, Lebanon and Turkey to Greece, and from there along the Balkan route via FYR Macedonia, Bosnia and Croatia or Serbia and Hungary to Austria. ${ }^{10}$ Natives living along this route have experienced the transit of refugees and how it disturbed everyday life in very similar ways as the residents of the Aegean islands. We therefore expect that our findings from Greece would also apply to these European countries, as well as several Northern African transit countries.

We believe that our findings have important implications for our theoretical understanding of the drivers of anti-refugee and anti-immigrant preferences. First, our study shows that in cases in which refugee arrivals are massive but also transient, they spark natives' hostility across a wide range of outcomes. Refugees left the arrival islands typically within 24 hours, which severely limits the potential for meaningful interaction between natives and refugees. In Allport's (1954) words, the best we could hope for in the present context is "casual contact," but not "acquaintance." Hence, we would not expect that conditions for the contact hypothesis to alleviate hostility are met here (Pettigrew 1998). For the same reason, however, we also do not expect that standard theories of economic or cultural concerns would apply (e.g., Golder 2003; Scheve, and Slaughter 2001), since refugees did not stay long enough on arrival islands to threaten the economic, political, or cultural prerogatives of the native population (Blalock 1967).

Even if the transient refugee arrivals did not threaten prerogatives of the local population, they did disrupt their lives. The inability of the local and European authorities to effectively manage the refugee flows and provide medical support and sanitary services caused chaotic scenes at the hotspots and sparked concerns about the spread of diseases. Our findings of a uniform effect of exposure to the refugee crisis across the sample suggest that this threat triggered exclusionary reactions not only among those already predisposed against immigration, but also among respondents who

\footnotetext{
${ }^{10}$ See Steinmayr (2018) for a study on how passing (and settled) refugees affects voting behavior in Austrian border municipalities.
}

otherwise would exhibit inclusionary attitudes and have not voted for (extreme) right-wing parties in the past.

Second, the fact that almost twelve months elapsed between the passing of the last refugee in March 2016 and the fielding of our survey in 2017 suggests that the exclusionary reactions documented here are not shortlived or an exacerbated reaction to a contemporaneous trigger, but rather entrenched and persistent. Hence, this finding is difficult to reconcile with the idea that repeated exposure to an outgroup alone, i.e., without meaningful contact, is sufficient to mitigate initial negative reactions (Enos 2014).

Third, we find that exposure to large numbers of asylum seekers causes natives to become more hostile not only toward refugees, but also toward economic migrants and Muslims, including native Muslims who have been residing in Greece for centuries. In times of enduringly high levels of refugee migration, this finding of a hostile spillover effect from one outgroup to another, unrelated minority is concerning from a normative perspective and an important avenue for future research.

\section{SUPPLEMENTARY MATERIAL}

To view supplementary material for this article, please visit https://doi.org/10.1017/S0003055418000813.

Replication materials can be found on Dataverse at: https://doi.org/10.7910/DVN/XGVQDT.

\section{REFERENCES}

Allport, Gordon W. 1954. The Nature of Prejudice. Cambridge, MA: Addison-Wesley.

Bansak, Kirk, Jens Hainmueller, and Dominik Hangartner. 2016. "How Economic, Humanitarian, and Religious Concerns Shape European Attitudes toward Asylum Seekers." Science 354 (6309): 217-22.

Bansak, Kirk, Jens Hainmueller, and Dominik Hangartner. 2017. "Europeans Support a Proportional Allocation of Asylum Seekers." Nature Human Behaviour 1 (7): 0133.

Barlow, Fiona Kate, Stefania Paolini, Anne Pedersen, Matthew J. Hornsey, Helena R. M. Radke, Jake Harwood, Mark Rubin, and Chris G. Sibley. 2012. "The Contact Caveat: Negative Contact Predicts Increased Prejudice More than Positive Contact Predicts Reduced Prejudice." Personality and Social Psychology Bulletin 38 (12): 1629-43.

Barlow, Fiona Kate, Winnifred R. Louis, and Miles Hewstone. 2009. "Rejected! Cognitions of Rejection and Intergroup Anxiety as Mediators of the Impact of Cross-Group Friendships on Prejudice." British Journal of Social Psychology 48 (3): 389-405.

Berg, Justin Allen. 2009. "Core Networks and Whites? Attitudes toward Immigrants and Immigration Policy." Public Opinion Quarterly 73 (1): 7-31.

Blalock, Hubert M. 1967. Toward a Theory of Minority-Group Relations. New York: Wiley.

Blumer, Herbert. 1958. "Race Prejudice as a Sense of Group Position." Pacific Sociological Review 1 (1): 3-7.

Bobo, Lawrence. 1983. "Whites' Opposition to Busing: Symbolic Racism or Realistic Group Conflict?" Journal of Personality and Social Psychology 45 (6): 1196-210.

Bobo, Lawrence, and Vincent L. Hutchings. 1996. "Perceptions of Racial Group Competition: Extending Blumer's Theory of Group Position to a Multiracial Social Context." American Sociological Review 61 (6): 951-72. 
Brader, Ted. 2006. Campaigning for Hearts and Minds: How Emotional Appeals in Political Ads Work. Chicago, IL: University of Chicago Press.

Brader, Ted, Nicholas A. Valentino, and Elizabeth Suhay. 2008. "What Triggers Public Opposition to Immigration? Anxiety, Group Cues, and Immigration Threat." American Journal of Political Science 52 (4): 959-78.

Branton, Regina, Gavin Dillingham, Johanna Dunaway, and Beth Miller. 2007. "Anglo Voting on Nativist Ballot Initiatives: The Partisan Impact of Spatial Proximity to the US-Mexico Border." Social Science Quarterly 88 (3): 882-97.

Brown, Rupert. 2000. "Social Identity Theory: Past Achievements, Current Problems and Future Challenges." European Journal of Social Psychology 30 (6): 745-78.

Cavaille, Charlotte and Jeremy Ferwerda. 2018. "How Distributional Conflict over In-Kind Benefits Generates Support for AntiImmigrant Parties.” Working Paper.

Chernozhukov, Victor, and Christian Hansen. 2005. "An IV Model of Quantile Treatment Effects.” Econometrica 73 (1): 245-61.

Connor, Walker. 1994. Ethnonationalism: The Quest for Understanding. Princeton: Princeton University Press.

Dinas, Elias, Konstantinos Matakos, Dimitrios Xefteris, and Dominik Hangartner. Forthcoming. "Waking up the Golden Dawn: Does Exposure to the Refugee Crisis Increase Support for ExtremeRight Parties?" Political Analysis.

Enos, Ryan D. 2014. "Causal Effect of Intergroup Contact on Exclusionary Attitudes." Proceedings of the National Academy of Sciences 111 (10): 3699-704.

Facchini, Giovanni, and Anna Maria Mayda. 2009. "Does the Welfare State Affect Individual Attitudes toward Immigrants? Evidence across Countries." The Review of Economics and Statistics 91 (2): 295-314.

Feldman, Stanley, and Karen Stenner. 1997. "Perceived Threat and Authoritarianism." Political Psychology 18 (4): 741-70.

Finseraas, Henning, and Andreas Kotsadam. 2017. "Does Personal Contact with Ethnic Minorities Affect Anti-Immigrant Sentiments? Evidence from a Field Experiment." European Journal of Political Research 56 (3): 703-22.

Forbes, Hugh Donald. 1997. Ethnic Conflict: Commerce, Culture, and the Contact Hypothesis. New Haven Yale University Press.

Golder, Matt. 2003. "Explaining Variation in the Success of Extreme Right Parties in Western Europe." Comparative Political Studies 36 (4): 432-66.

Gravelle, Timothy B. 2016. "Party Identification, Contact, Contexts, and Public Attitudes toward Illegal Immigration." Public Opinion Quarterly 80 (1): 1-25.

Gravelle, Timothy B. 2018. "Partisanship, Local Context, Group Threat, and Canadian Attitudes towards Immigration and Refugee Policy." Migration Studies 6 (3): 448-67.

Hainmueller, Jens, and Daniel J. Hopkins. 2014. "Public Attitudes toward Immigration." Annual Review of Political Science 17: 225-49.

Hainmueller, Jens, Dominik Hangartner, and Giuseppe Pietrantuono. 2017. "Catalyst or Crown: Does Naturalization Promote the Long-Term Social Integration of Immigrants?" American Political Science Review 111 (2): 256-76.

Hardin, Russell. 1997. One for All: The Logic of Group Conflict. Princeton, NJ: Princeton University Press.

Hetherington, Marc J., \& Jonathan D. Weiler. 2009. Authoritarianism and Polarization in American Politics. Cambridge: Cambridge University Press.

Hopkins, Daniel J. 2010. "Politicized Places: Explaining Where and When Immigrants Provoke Local Opposition." American Political Science Review 104 (1): 40-60.

Ivarsflaten, Elisabeth. 2005. "Threatened by Diversity: Why Restrictive Asylum and Immigration Policies Appeal to Western Europeans." Journal of Elections, Public Opinion \& Parties 15 (1): 21-45.

Kaufmann, Eric, and Gareth Harris. 2015. "'White Flight' or Positive Contact? Local Diversity and Attitudes to Immigration in Britain." Comparative Political Studies 48 (12): 1563-90.

Keeter, Scott, Nick Hatley, Courtney Kennedy, and Arnold Lau. 2017. "What Low Response Rates Mean for Telephone Surveys." Working Paper, Pew Research Center.

Marbach, Moritz, and Guido Ropers. 2018. "Not in My Backyard: Do Increases in Immigration Cause Political Violence?" Working Paper.

Mayda, Anna Maria. 2006. "Who Is against Immigration? A CrossCountry Investigation of Individual Attitudes toward Immigrants." The Review of Economics and Statistics 88 (3): 510-30.
McConnell, Allen R., and Jill M. Leibold. 2001. "Relations Among the Implicit Association Test, Discriminatory Behavior, and Explicit Measures of Racial Attitudes." Journal of Experimental Social Psychology 37 (5): 435-42.

McLaren, Lauren M. 2003. "Anti-Immigrant Prejudice in Europe: Contact, Threat Perception, and Preferences for the Exclusion of Migrants." Social Forces 81 (3): 909-36.

Neumayer, Eric. 2005. "Bogus Refugees? The Determinants of Asylum Migration to Western Europe." International Studies Quarterly 49 (3): 389-409.

Olsson, Ulf. 1979. "Maximum Likelihood Estimation of the Polychoric Correlation Coefficient." Psychometrika 44 (4): 443-60.

Paluck, Elizabeth Levy, and Donald P. Green. 2009. "Prejudice Reduction: What Works? A Review and Assessment of Research and Practice." Annual Review of Psychology 60: 339-67.

Paluck, Elizabeth L., Seth A. Green, and Don Green. 2018. "The Contact Hypothesis Re-evaluated." Behavioral Public Policy, Forthcoming.

Pettigrew, Thomas F. 1998. "Intergroup Contact Theory." Annual Review of Psychology 49 (1): 65-85.

Pettigrew, Thomas F., and Linda R. Tropp. 2006. "A Meta-Analytic Test of Intergroup Contact Theory." Journal of Personality and Social Psychology 90 (5): 751.

Pettigrew, Thomas F., and Linda R. Tropp. 2008. "How Does Intergroup Contact Reduce Prejudice? Meta-Analytic Tests of Three Mediators." European Journal of Social Psychology 38 (6): 922-34.

Putnam, Robert D. 2007. "E Pluribus Unum: Diversity and Community in the Twenty-First Century the 2006 Johan Skytte Prize Lecture." Scandinavian Political Studies 30 (2): 137-74.

Ravenstein, Ernst Georg. 1885. "The Laws of Migration.” Journal of the Statistical Society of London 48 (2): 167-235.

Revilla, Melanie A, Willem E. Saris, and Jon A. Krosnick. 2014. "Choosing the Number of Categories in Agree-Disagree Scales." Sociological Methods \& Research 43 (1): 73-97.

Salmon, Charles T., and John Spicer Nichols. 1983. "The NextBirthday Method of Respondent Selection." Public Opinion Quarterly 47 (2): 270-6.

Scacco, Alexandra, and Shana S. Warren. 2018. "Can Social Contact Reduce Prejudice and Discrimination? Evidence from a Field Experiment in Nigeria." American Political Science Review 112 (3): 654-77.

Scheve, Kenneth F., and Matthew J. Slaughter. 2001. "Labor Market Competition and Individual Preferences over Immigration Policy." Review of Economics and Statistics 83 (1): 133-45.

Schlueter, Elmar, and Peer Scheepers. 2010. "The Relationship between Outgroup Size and Anti-Outgroup Attitudes: A Theoretical Synthesis and Empirical Test of Group Threat -and Intergroup Contact Theory." Social Science Research 39 (2): 285-95.

Sniderman, Paul M., Louk Hagendoorn, and Markus Prior. 2004. "Predisposing Factors and Situational Triggers: Exclusionary Reactions to Immigrant Minorities." American Political Science Review 98 (1): 35-49.

Steinmayr, Andreas. 2018. "Contact Matters: Exposure to Refugees and Voting for the Far-Right." Working Paper.

Stenner, Karen. 2005. The Authoritarian Dynamic. Cambridge: Cambridge University Press.

Stock, James H., and Motohiro Yogo. 2002. "Testing for Weak Instruments in Linear IV Regression." Working Paper 284, National Bureau of Economic Research.

Sturgis, Patrick, Ian Brunton-Smith, Jouni Kuha, and Jonathan Jackson. 2014. "Ethnic Diversity, Segregation and the Social Cohesion of Neighbourhoods in London." Ethnic and Racial Studies 37 (8): 1286-309.

UNHCR. 2016. "Emergency Information Sharing Web Portal." Available at http://data.unhcr.org/mediterranean/documents.php.

Van Laar, Colette, Shana Levin, Stacey Sinclair, and Jim Sidanius. 2005. "The Effect of University Roommate Contact on Ethnic Attitudes and Behavior." Journal of Experimental Social Psychology 41 (4): 329-45.

Vertier, Paul, and Max Viskanic. 2018. "Dismantling the 'Jungle': Migrant Relocation and Extreme Voting in France." CESifo Working Paper Series 6927, CESifo Group Munich.

Wike, Richard, Bruce Stokes, and Katie Simmons. 2016. "Europeans Fear Wave of Refugees Will Mean More Terrorism, Fewer Jobs.” In Pew Research Center, Available at: http://pewrsr.ch/29ziWV3.

Zorlu, Aslan. 2017. "Attitudes toward Asylum Seekers in Small Local Communities." International Migration 55 (6): 14-36. 